\title{
Patterns of survival and roost switching in an African insectivorous bat
}

\author{
Ara Monadjem ${ }^{1,2}$, Robert A. McCleery ${ }^{3} \&$ Bret Collier $^{4}$
}

${ }^{1}$ All Out Africa Research Unit, Department of Biological Sciences, University of Swaziland, Private Bag 4, Kwaluseni, Swaziland

${ }^{2}$ Mammal Research Institute, Department of Zoology and Entomology, University of Pretoria, Private Bag 20, Hatfield 0028, Pretoria, South Africa

${ }^{3}$ Department of Wildlife Ecology and Conservation, University of Florida, Gainesville, Florida, USA

${ }^{4}$ School of Renewable Natural Resources, Louisiana State University, Baton Rouge, LA 70803, USA

\section{Correspondence}

Ara Monadjem, All Out Africa Research Unit, Department of Biological Sciences, University of Swaziland, Private Bag 4, Kwaluseni, Swaziland. Tel: +268 25184011; Fax: +268 25185276. Email address: $\underline{\text { ara@ uniswa.sz }}$

\section{Keywords}

Apparent annual survival, Nycteris thebaica, roost switching, Egyptian slit-faced bats

\begin{abstract}
Variation in survival over time and amongst age and sex classes drives population dynamics for a large majority of long-lived species and is critical to understanding species demography. For highly mobile species that actively move among potential breeding locations, coupling survival information with estimates of locational fidelity provides the basis for our understanding of species population dynamics. We studied the effect of time, age and sex class, and climatic variables on survival and roost transition probabilities on a population of Egyptian slit-faced bats
\end{abstract}


in Swaziland from 1450 marked individuals from 16 roosts over a 10 year period. We then used variance components analysis to estimate average annual survival and associated temporal process variance. Annual apparent survival varied with sex and age, being highest in adult males and lowest in juvenile females. We did not find evidence of survival being influenced by climatological factors as commonly observed in temperate bats. Roost switching occurred frequently, with more transitions to roosts harboring larger number of bats. Furthermore, the probability of transitioning to another roost was related to its distance from the original roost. The dispersal patterns revealed in this study were consistent with the fission-fusion dynamics common for colonial bats.

\section{Introduction}

Variation in demographic parameters across time, space, and amongst life history stages drive species population dynamics. Population growth rates of slowly maturing, long-lived species are typically most sensitive to variability in adult survival (Stearns, 1983). In addition, for longlived species with specific habitat for reproduction and development of young, individuals have to take annual decisions to return to a previous used location (site fidelity), or move to a new location (Beletsky \& Orians, 1991; Hoover, 2003; Matthiopoulos 2005). For mobile species, these decisions are likely driven by some combination of previous experience, physiological state and current environmental conditions (Serrano et al., 2001; Papadatou et al., 2009; Papadatou et al., 2011). Thus, by combining information on population survival with estimates of locational fidelity we can better understand the population dynamics of a long-lived mobile species. 
There is a paucity of information on population dynamics, movement ecology, and social structures of bats (Entwistle et al., 2000; Hillen et al. 2010; Kerth et al., 2011). Bat population dynamics are assumed to be driven by adult survival and dispersal from natal sites as fecundity is relatively constant (Greenwood, 1980; Barclay \& Harder, 2003). Whereas survivorship information is requisite for linking the population dynamics to environmental conditions, survival has only been estimated for a handful of species (e.g. Sendor \& Simon, 2003; Schaub et al., 2007; Schorcht et al., 2009; Ellison, 2010), including in African ecosystems (Monadjem, 2005).

Bat populations in temperate climates often show dispersal patterns with young males leaving natal roosts while females remain in a typical philopatric mating system (Burland \& Worthington Wilmer, 2001; Kerth, 2008). Regardless of whether population movements are driven by adults or juveniles, it is critical to understand those factors and mechanisms which influence the complex dispersal and movement patterns seen in bats. However, little is known about the drivers of bat population dynamics, although research has suggested that population density, environmental conditions and distance between roost sites should have the strongest influences on bat movements and demography (Gaines \& McClenaghan, 1980; Tranjano 1996; Kerth, 2008). Accordingly, we hypothesize that relative population density per roost site, environmental conditions, and distance between roost sites would have the strongest influences on bat demography and population structure.

The goal of our work was to evaluate drivers of survival and roost switching for the Egyptian slit-faced bat in day roosts in north-eastern Swaziland. In addition to estimating annual variation in apparent survival and movements relative to sex and age class, we evaluated if 
survival or roost switching were related to measures of climate, population densities, distance traveled, and age class of bats.

\section{Methods and Materials}

\section{Study species}

The Egyptian slit-faced bat Nycteris thebaica (Nycteridae: Chiroptera) is a small (ca. 12g), colonially roosting African insectivorous bat that shows high fidelity to its natal region (Bowie et al., 1999; Monadjem, 2005; Monadjem et al., 2010a). It utilizes a variety of shelters as day roosts including caves, burrows, culverts and tree hollows; using the same day shelters during the breeding and non-breeding periods (Monadjem et al., 2010a) and travelling on average $1.1 \mathrm{~km}$ each night to the foraging areas which have separate night roosts located within them (Monadjem et al., 2009). In southern Africa, mating takes place in winter and births occur four months later at the beginning of the wet season (Bernard, 1982). This species is not known to hibernate (Monadjem et al., 2010a). Typical for bats, the Egyptian slit-faced bat is a long-lived species with individuals surviving for at least eight years (Monadjem, 2006).

\section{Study site and data collection}

Our study was conducted at Mlawula Nature Reserve $\left(26^{\circ} 11^{\prime} \mathrm{E}, 31^{\circ} 59^{\prime} \mathrm{E}, 160 \mathrm{~m}\right.$ above sea level) in north-eastern Swaziland where an active marking program for Egyptian slit-faced bats has been conducted since 1998 (Monadjem, 2005). The climate in this part of Swaziland is subtropical with hot, wet summers and dry, cool winters. Mean daily temperatures for January and July are $26^{\circ} \mathrm{C}$ and $18^{\circ} \mathrm{C}$, respectively, while mean annual rainfall ranges from $550-725 \mathrm{~mm}$. The dominant vegetation community is Acacia savanna with Acacia nigrescens, A.tortilis, 
Ziziphus mucronata, Sclerocarya birrea and Dichrostachys cinerea being characteristic trees (Monadjem \& Reside 2008; Monadjem et al., 2009; Monadjem et al., 2010b). Egyptian slitfaced bats utilize, as a day roost, a series of culverts passing beneath the road leading to Mlawula Nature Reserve (Monadjem, 1998; Monadjem, 2001). These culverts range from 60-100 cm wide and up to $50 \mathrm{~m}$ long.

Following methods detailed in Monadjem (2005) we captured bats in the culverts by pushing a wooden "shield" through the culvert into a large sweep net placed over the other end. Additionally, we blocked the opposite culvert end to prevent bats that had maneuvered past the shield from leaving the culvert. The process was repeated until all bats within a culvert had been captured. All captured bats were sexed, aged and were fitted with metal bat-bands which were attached around the forearm. While negative and neutral impacts of bands on bat health have been found in other studies (Baker et al., 2001; Happold \& Happold, 1998; Herreid et al., 1960) we did not record injuries (such as swelling or rip of the patagium) caused by band application or wear, but noted that few individuals that had such injuries were healed on subsequent capture occasions, similar to results reported by Happold \& Happold (1998). Our study was conducted in accordance with the guidelines published in Guidelines of the American Society of Mammalogists for the use of Wild Mammals in Research (Gannon \& Sikes 2007) and under a research permit from the Swaziland National Trust Commission.

We categorized all captured individuals into two age classes: juveniles (including subadults) and adults. Juveniles/sub-adults were defined as the "first-year" age class and were identifiable by size and pelage, which is typically greyer than that of the adults (Monadjem, 2001). Capture operations were conducted at all culverts during the same day, but at irregular intervals within a year, ranging from one to four capture occasions per year. Capture occasions 
showed little within year variation, being conducted primarily between November and February each year. Therefore, we collapsed all capture-recapture data into year-specific capture occasions for subsequent analysis.

\section{Capture-recapture analysis}

We used an open population, multi-state, capture-recapture approach (Hestbeck et al., 1991; Schaub et al., 2004) wherein we estimated parameters for apparent survival ( $\Phi)$, recapture probability $(p)$, and strata transition probability $(\Psi)$ between and among roost sites over the course of our study. We developed a suite of candidate models that described a set of biological hypotheses relative to our expectations of Egyptian slit-faced bat population dynamics. We hypothesized that survival rates would be influenced by temporal and climate factors such as rainfall (model 14, Table 1), cold weather (model 13) and that annual variation would impact survival rates of all bats (model 12). We also hypothesized that survival rates would be influenced by characteristics of the bats such as sex (model 8), age (model 7), and cohorts (model 11). For bat cohorts, we hypothesized that cohorts of bats born during the same season would have similar survival rates driven by fluctuations in annual conditions. Finally, we hypothesized that survival would be influenced by combinations of interacting biological traits (age, sex) and temporal and climate variation (models 1-6, 9 and 10).

For our data, each roost (culvert) capture location $(\mathrm{n}=16)$ was classified as a stratum (state) and captured individuals were classified to a stratum during each occasion. As an example, a simplified encounter history such as AB0A would imply that the bat was captured at roost A during sampling occasion 1, recaptured at roost B during sampling occasion 2, not recaptured during sampling occasion 3, and recaptured during sampling occasion 4 at roost A. 
Table 1 The list of candidate models for Egyptian slit-faced bats captured and marked in day roosts in north-eastern Swaziland between 1998 and 2008. Model parameters used for candidate model creation included Sex (male or female), Age (juvenile or adult), Cohort (parameter estimating time-since-marking on apparent survival), Stratum (parameter representing constant transition probability between strata), Rain (total rainfall during year), Cold (number of days with temperatures dropping below $5^{\circ} \mathrm{C}$ ) as well as Time (a parameter for time effects) on both the survival and the recapture process.

\begin{tabular}{lcllll}
\hline Survival & Transition & Recapture & $\mathrm{k}$ & $\mathrm{AIC}_{\mathrm{c}}$ & $w_{i}$ \\
\hline 1. Sex*Age*Time + Cohorts & $\sim$ Stratum & $\sim$ time & 96 & 10861 & 1 \\
2. Sex*Age*Time & $\sim$ Stratum & $\sim$ time & 145 & 10873 & $<0.01$ \\
3. Sex*Time + Cohorts & $\sim$ Stratum & $\sim$ time & 82 & 10887 & 0 \\
4. Cold + Age + Cohorts & $\sim$ Stratum & $\sim$ time & 81 & 10906 & 0 \\
5. Rain+ Age + Cohorts & $\sim$ Stratum & $\sim$ time & 81 & 10906 & 0 \\
6. Age*time + Cohorts & $\sim$ Stratum & $\sim$ time & 80 & 10906 & 0 \\
7. Age & $\sim$ Stratum & $\sim$ time & 67 & 10909 & 0 \\
8. Sex & $\sim$ Stratum & $\sim$ time & 67 & 10909 & 0 \\
9. Sex*cold & $\sim$ Stratum & $\sim$ time & 69 & 10910 & 0 \\
10. Sex*rain & $\sim$ Stratum & $\sim$ time & 69 & 10911 & 0 \\
11. Time + Cohorts & $\sim$ Stratum & $\sim$ time & 74 & 10938 & 0 \\
12. Time & $\sim$ Stratum & $\sim$ time & 70 & 10963 & 0 \\
13. Cold & $\sim$ Stratum & $\sim$ time & 67 & 10986 & 0 \\
14. Rain & $\sim$ Stratum & $\sim$ time & 67 & 10987 & 0 \\
\hline & & & & & 0 \\
\hline
\end{tabular}

AICc, Akaike information criterion adjusted for small sample bias.

Using this structure, we created capture histories for each bat $(n=1450)$ based on the 10 years of capture data and we used those data to evaluate survival and movement transitions. In some situations, transitions between specific roost sites occurred with very low frequency $(<3$ total 
transitions between strata during our study) or had no transitions between roost sites. In those cases, we fixed the parameters for those transitions to zero to facilitate with model optimization.

Bat survival tends to be variable and may follow annual cycles (Schorcht et al., 2009), sometimes due to cyclic environmental conditions (Pryde et al., 2005). Thus, we evaluated the impacts of time-specificity relative to annual variation in survival (Time), the impact of both total rainfall (Rain) and the number of days with temperatures dropping below $5^{\circ} \mathrm{C}(\mathrm{Cold})$ as measured by the Mlaula Meteorological Station, Royal Swazi Sugar Corporation which was less than $10 \mathrm{~km}$ from our study site. We also evaluated the effects of sex (Sex), age (Age), and an age-based time-since-marking (TSM) parameterization on estimates of annual apparent survival on cohorts of the Egyptian slit-faced bat born during the same season (Cohorts). The TSM model allows for separation of these age/cohort segments and generally explains the data better than standard fully time dependent models (Sandercock et al., 2000). In many capture-recapture situations, exact age of captured individuals is often unknown, as was the case in our study. In such a situation, separation of temporal variation in demography from age-specific variation in demography is impossible as age and time are equivalent in model parameterization. In this situation, a logical approach is to expect that individuals of the $i^{\text {th }}$ age class (e.g., adults of unknown age) will be impacted by the same environmental factors as individuals of known age (e.g., individuals captured as juveniles at $t-3$ that are now adults of age 3 ) during a specific capture occasion. As it is often expected that differences in demography are a function of the environmental conditions relative to the time an individual has been marked, the TSM models allowed us to constrain our analysis under assumptions that survival for the year after marking was different from survival in subsequent years that an individual was alive. 
As the Egyptian slit-faced bat is a colonial species and shows fairly high fidelity to its natal region (Monadjem, 2005), we modeled recapture rates using a time-specific parameter wherein recapture rates were expected to be fully time-dependent. We chose to use temporal models for recapture rates because if bats were present and available to be captured in our study roosts, then we were guaranteed to have captured them (due to the sampling methods and ability to close off each culvert during capture events). Thus, we assumed that any variability in recapture rates was likely tied to temporal variation in bat survival (and hence return rates) rather than heterogeneity in the capture process (Otis et al., 1978).

We developed a candidate set of 13 models which we used to evaluate the above biological hypotheses relative to our study design (Table 1). We conducted analyses using program MARK v. 6.1 (White \& Burnham, 1999) via RMark v. 2.1.7 (Laake, 2013) in R version 3.0.2 (R Development Core Team, 2013). We used an information-theoretic approach (Burnham \& Anderson, 2002) to evaluate model parsimony and ranked models based on $\mathrm{AIC}_{\mathrm{c}}$ (Akaike Information Criterion adjusted for small sample bias; Burnham \& Anderson, 2002). In addition, we used a variance components approach (Burnham \& White, 2002) to estimate mean survival for the course of the study and associated process variance of annual apparent survival such that the associated variance provides a representation of the inherent variation in survival over time. Based on preliminary data analysis before the entire dataset was collected, we identified that models with time specificity in the recapture rates were much better supported than all other options for recapture rate modeling. Hence herein we used only a $p(t)$ model for recapture rate estimation.

We used an "analysis of variance" to compare the average probability of bats staying in a particular culvert to the average probability that bats left a particular culvert. To determine if 
culverts that retained bats were more likely to receive bats from other culverts we regressed the probability of bats transitioning to the same culvert with the average probability of bats from the other 13 culverts transitioning to that culvert. Similarly, we determined if bats transitioned to roosts with more bats by regressing average transition rates to a culvert against the average number of bats captured annually in each culvert. Finally, we conducted a Mantel's test (Hood, 2010) to determine if the probability of transitioning from one culvert to another was a function of distance between culverts.

\section{Results}

\section{Summary statistics}

A total of 1450 individual Egyptian slit-faced bats were banded from 1998 to 2008. These bats were recaptured 1779 times. Of the total number of individuals captured 875 were female, 575 male. With respect to age, 752 individuals were originally captured as juveniles/sub-adults, and the remaining 698 individuals as adults. As juveniles, the sex ratio of males $(n=374)$ and females $(n=378)$ did not differ significantly from parity. The number of individuals captured per year varied from 50 individuals in 2008 to over 400 individuals in 2000, with over 250 captured in most years. The number of individuals captured across all years at each of the 16 roost sites varied considerably, ranging from 19 captures up to 602 captures. More than 200 captures were recorded at seven of the roost sites, with six sites recording less than 100 captures.

\section{Survival}

We found little support for models that included any of the climatic variables. The best fitting model, model 1 (S(sex*age*time + TSM for juveniles), p(time), $\Psi($ stratum); Table 1) indicated 

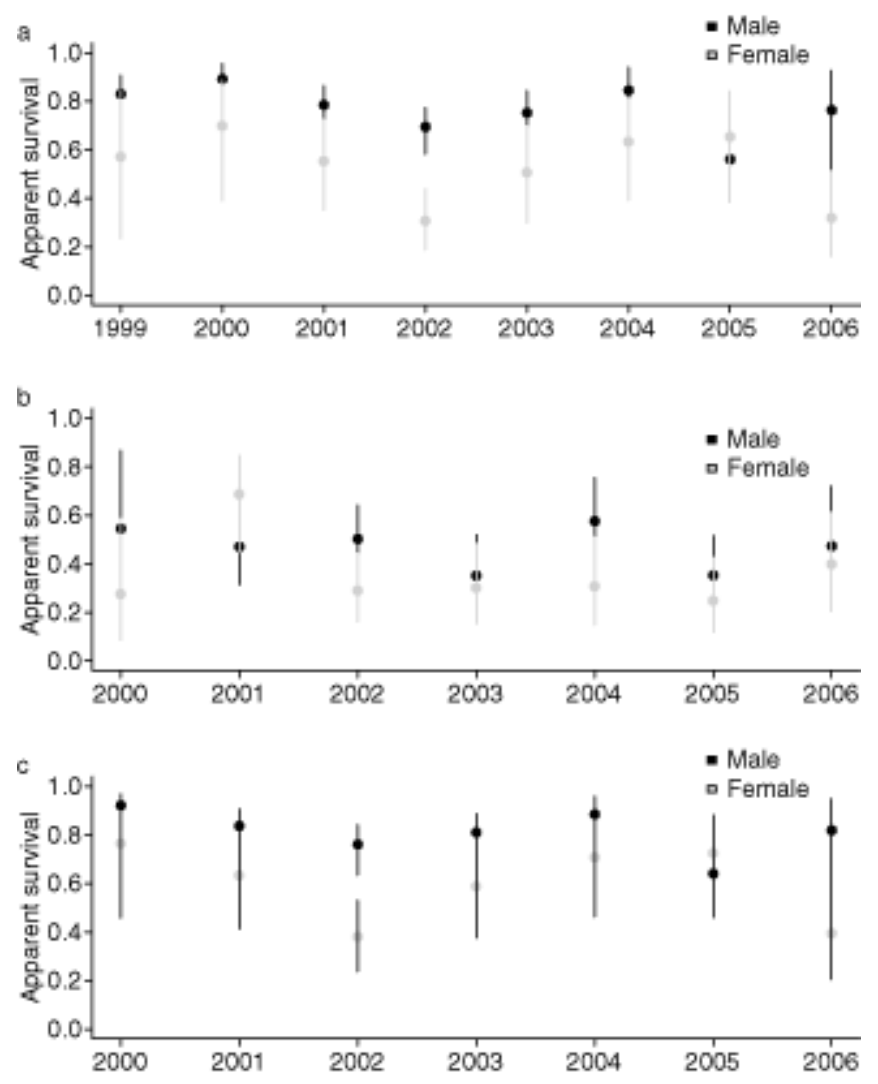

Figure 1 Estimated annual survival (95\% CI) of Egyptian slit-faced bats in north-eastern Swaziland for: (A) adult males and females; (B) juvenile males and females; and (C) annual apparent survival estimates based on a timesince-marking parameterization of survival for males and females.

that survival varied temporally by sex and age class (Fig. 1). Juvenile survival was lower than adult survival for most years, yet annual fluctuations in the survival of juveniles captured during the same year were similar in magnitude and direction to patterns of adult survival. Mean survival estimates and associated process standard deviation based on the best fitting candidate model from our variance components analysis were: 0.34 (0.11) for juvenile females; $0.51(0.11)$ for adult females; and $0.58(0.11)$ for the juvenile females time-since-marking parameterization, respectively. For males, mean survival and associated process standard deviation estimates were; $0.43(0.11)$ for juvenile males, $0.75(0.08)$ for adult males, and $0.80(0.07)$ for juvenile 
male time-since-marking parameterization, respectively. Overall, recapture probabilities were high from 2000-2008 $(0.73(\mathrm{SE}=0.06), 0.72(\mathrm{SE}=0.05), 0.70(\mathrm{SE}=0.04), 0.62(\mathrm{SE}=0.04)$, $0.62(\mathrm{SE}=0.04), 0.42(\mathrm{SE}=0.04), 0.61(\mathrm{SE}=0.05), 0.19(\mathrm{SE}=0.03), 0.30(0.04))$, respectively.

\section{State transitions}

Overall, our model selection results indicated no differences in annual movements among day roosts based on either age or sex. In general, bats were most likely to return to the culvert where they were originally captured (diagonal in Table 2); however, bats still moved liberally among various culverts (Table 2). Accordingly, we found no statistical difference ( $f=0.706, p=$ $0.408)$ between the probabilities of bats staying in the same culvert $(0.46,95 \% \mathrm{CI}=0.29-0.61)$ or moving to another roost site $(0.54,95 \% \mathrm{CI}=0.38-0.71)$.

Bats were more likely to move to a culvert that on average had more bats $(\mathrm{f}=6.44, \mathrm{p}=$ $0.026, r^{2}=0.349$ ). However, we found no relationship between the probability of bats staying in a particular culvert and the probability of bats from others culverts moving to it ( $\mathrm{f}=0.621, \mathrm{p}=$ 0.446). As expected, we found that bats were less likely to transition to culverts that were further away (Mantel, $\mathrm{r}=-0.304, \mathrm{p}=0.002)$. 
Table 2 Transition probability estimates and associated standard errors for transitions between roosts (strata) of Egyptian slit-faced bats captured and marked in north-eastern Swaziland 1998-2008. The columns represent the 'to' strata designation (current location in time $t+1$ ) while the row's represent the 'from' strata (location in time $t$ )

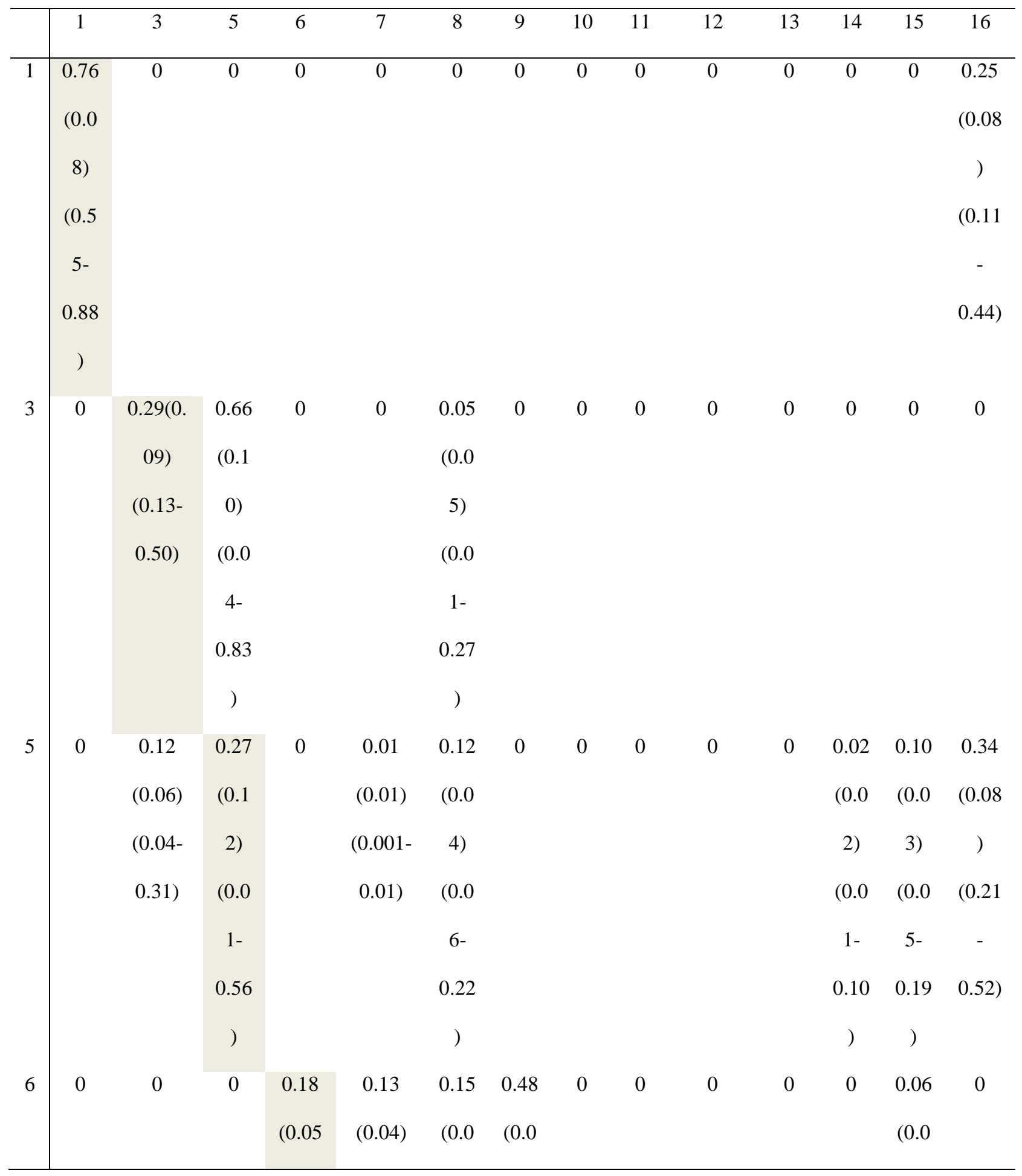




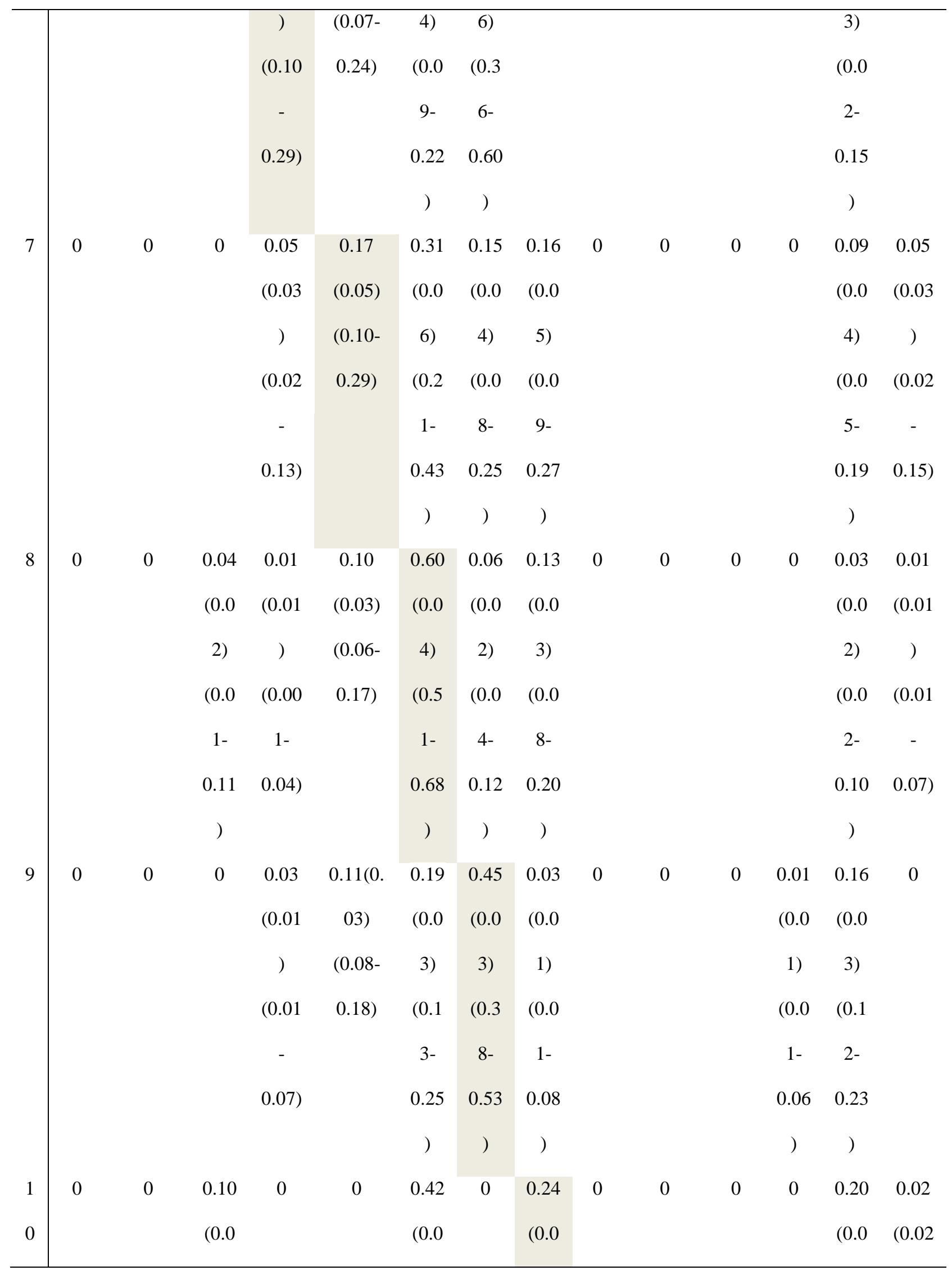




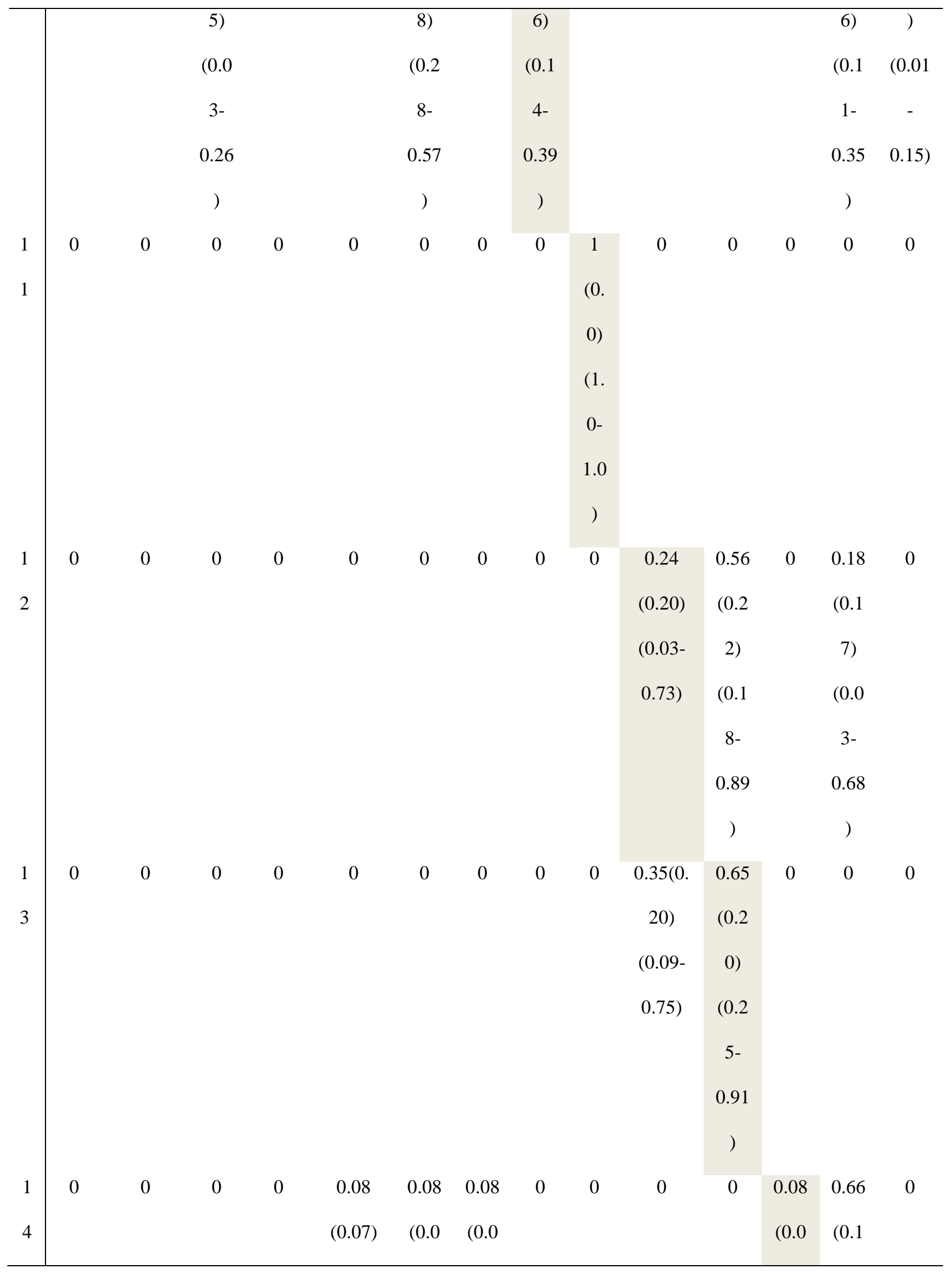




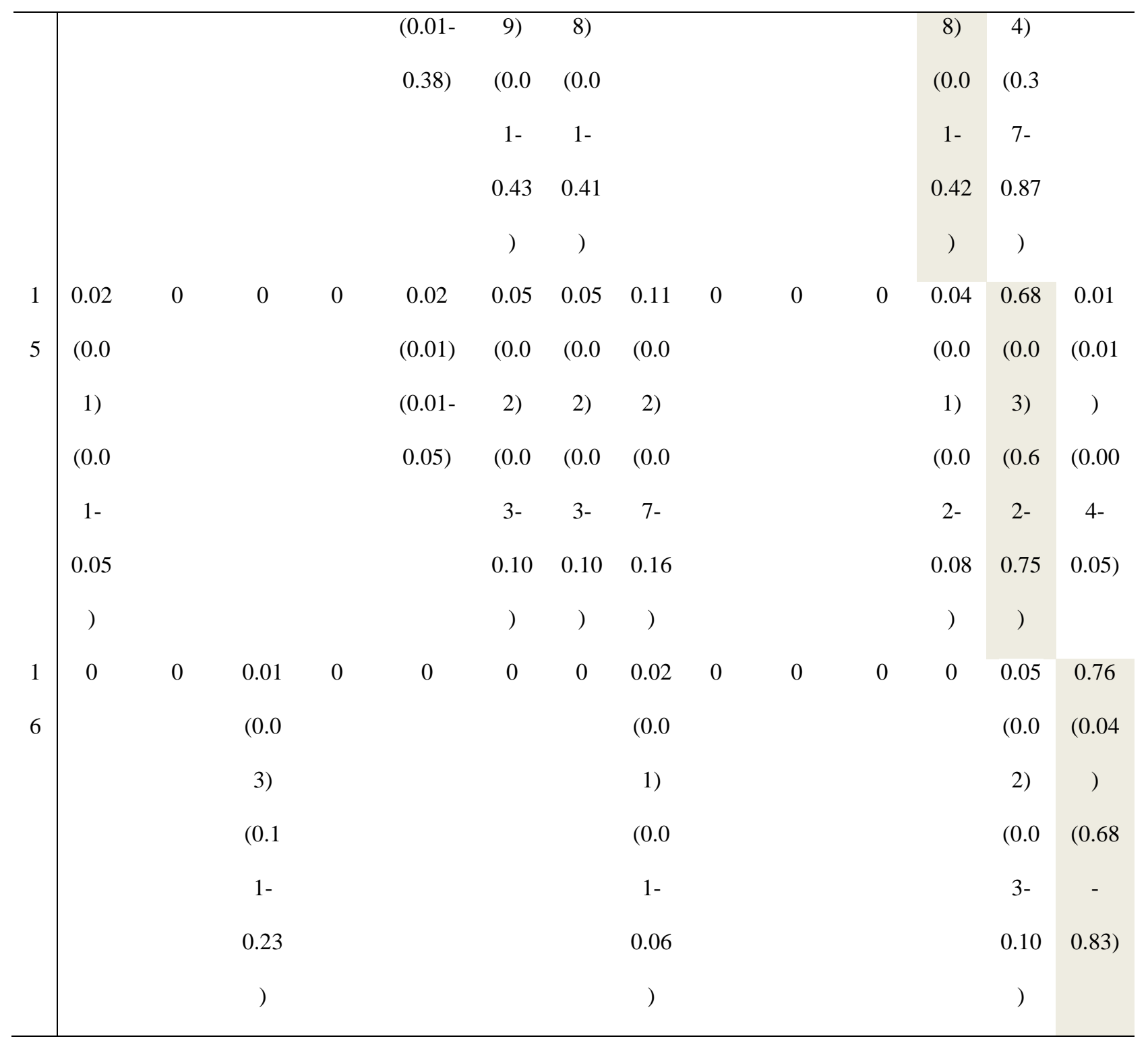

\section{Discussion}

We followed the fate of Egyptian slit-faced bats over a 10 year period and applied multistate capture-recapture methods to estimate survival and transition rates, furthering our understanding of tropical bat demography (Baker et al., 2001; O'Shea et al., 2004). Our results indicated that survival of adults was higher than juveniles, and male survival was consistently higher than female survival. 
Surprisingly, survival of Egyptian slit-faced bats was not associated with those climatic factors we evaluated. This contrasts with previous and limited work on temperate bats where such a linkage between climatic variation and bat survival has been reported (Pryde et al., 2005; Ellison, 2010). This may possibly be due to the subtropical climate placing less stress on the thermoregulation requirements of bats compared with a temperate environment. Additionally, because our study was located in a matrix of intense agricultural production that is irrigated yearround there may have been minimal variation in food availability throughout the year. Nonetheless, whatever the reason for this relationship, our research makes it clear that assumptions about temperate bats cannot be uncritically applied to subtropical regions like southern Africa. It also raises interesting questions about what mechanisms may be driving variation in survival rates in such regions.

For bat species in which survival has been shown to vary between males and females, this has been attributed to differential roost use between the sexes (Hoyle et al., 2001, Pryde et al., 2005). Females tend to be more gregarious roosters than males possibly providing thermal advantages for females in temperate climates where their survival is often higher than males (Boyd \& Stebbings, 1989; Gerell \& Lundberg, 1990; Pryde et al., 2005). We speculate that the differences in survival observed in our study are also a function of male dispersal away from the communal roosting sites which are dominated by females (Monadjem, 2005). The sex ratios of adult Egyptian slit-faced bats utilizing communal roosts in this study were heavily biased to females for most of the year (Monadjem, 2005), suggesting that males generally roost elsewhere. Radio-tracking of this population showed that some individuals roosted in antbear holes (Monadjem et al., 2009), which may represent roost sites of single males away from the female colonies in the culverts. However, in contrast to the temperate studies mentioned above, male 
Egyptian slit-faced bats showed higher survival rates than females, suggesting that the possible thermal advantages of communal roosting do not outweigh the costs of group living (such as competition for local resources and disease transmission) (Barclay \& Harder, 2003). This raises the possibility that roosting singly may increase survival for the males, although the mechanism is not currently understood.

Lower estimated survival of juveniles compared with adults is not surprising and has been reported for a number of bat species (Hoyle et al., 2001; O'Shea et al., 2004; Schorcht et al., 2009). Typically in bats, juvenile males are the primary dispersers (Kerth et al., 2002), which has been used to explain the lower survival of juvenile males compared with juvenile females (Cam et al., 2004). However, in our study, juvenile males experienced higher apparent survival rates (Fig. 1b) than juvenile females, suggesting that juvenile dispersal, if occurring in Nycteris, may not necessarily lead to higher mortality.

Bats moved liberally to different roosts (culverts), transitioning from the previous year's roost to a new roost site more than half (> 50\%) of the time. However, bats in some roosts were much more likely to return to the same roost. This pattern of roost fidelity shown by some bats is thought to occur when the benefits of staying in the roost (temperature regulation, protection from predators, familiarity, known social relationships and successful rearing of young) outweigh the costs of leaving the roost (Lewis, 1995). In our study, increased fidelity of bats to a particular roost was not associated with increased rates of transition to that roost site. In other words there was a historical component involved; bats in popular roosts (i.e. those that showed high fidelity) comprised bats previously roosting in these roosts and bats that had not previously used these roosts did not switch to them. This suggests that the potential benefits of staying in a particular roost are not readily apparent to bats unfamiliar with a particular roost. Nonetheless, 
bats did move to culverts with high numbers of roosting bats, possibly using this (the size of the roost) as a cue for roost selection.

The dispersal patterns revealed in this study were not consistent with the philopatric systems typically found in temperate climates (Burland \& Worthington Wilmar, 2001; Kerth, 2008). We found no difference between adults and juveniles and males and females in their rates of transition among roosts. Bats were more likely to transition to nearby roost sites and those with larger bat populations, forming even larger aggregation of bats. The social consequences of roost movements are complex and difficult to decipher without information on relatedness of individuals and groups. Nonetheless, the patterns demonstrated here are at least consistent with fission-fusion dynamics common for colonial bats (Kerth et al., 2011). Fission occurs when groups of bats leave a roost to a new roost and fusion occurs when these groups reform. What we cannot determine from our current analysis is if movement between roosts occurred individually or in groups.

In conclusion the patterns of survival and social behaviour of the Egyptian slit-faced bat cannot be understood from previous studies of bat survival (typically conducted in temperate environments). This species provides is an excellent opportunity for understanding complex patterns of survival not driven by climatic factors, as is the case in many temperate bats.

\section{Acknowledgements}

We appreciate Mduduzi Ngwenya's assistance with field operations. Peter Taylor provided the original bat bands used in our study. Kim Roques and Sikhumbuzo Dlamini are thanked for granting us permission to work in Mlawula Nature Reserve and Mbuluzi Game Reserve 
respectively. The Swaziland National Trust Commission provided the relevant permit to capture and band bats. Two anonymous referees greatly improved an earlier version.

\section{References}

Baker, G.B., Lumsden, L.F., Dettmann, E.B., Schedvin, N.K., Schulz, M., Watkins, D. \& Jansen, L. (2001). The effect of forearm bands on insectivorous bats (Microchiroptera) in Australia. Wildlife Research 28, 229-237.

Barclay, R.M.R. \& Harder, L.M. (2003). Life histories of bats: life in the slow lane. In Bat ecology: 209-252. Kunz, T.H. \& Fenton, M.B. (Eds). Chigaco: University of Chicago Press.

Beletsky, L.D. \& Orians, G.H. (1991). Effects of breeding experience and familiarity on site fidelity in female red-winged black birds. Ecology 72, 787-796.

Bernard, R.T.F. (1982). Female reproductive cycle of Nycteris thebaica (Microchiroptera) from Natal, South Africa. Z. Saugetierkunde 47, 12-18.

Bowie, R.C.K., Jacobs, D.S. \& Taylor, P.J. (1999). Resource use by two morphologically similar insectivorous bats (Nycteris thebaica and Hipposideros caffer). S. Afr. J. Zool. 34, 27-33.

Burland, T.M. \& Worthington Wilmer, J. (2001). Seeing in the dark: molecular approaches to the study of bat populations. Biological Reviews 76, 389-409.

Burnham, K.P. \& Anderson, D.R. (2002). Model selection and multi-model inference. 2nd edn. New York: Springer-Verlag.

Burnham, K.P. \& White, G.C. (2002). Evaluation of some random effects methodology applicable to bird ringing data. J. Appl. Stats. 29, 245-264 
Boyd, I.L. \& Stebbings, R.E. (1989). Population changes of brown long-eared bats (Plecotus auritus) in bat boxes at Thetford Forest. J. Appl. Ecol. 26, 101-112.

Cam, E., Oro, D., Pradel, R. \& Jimenez, J. (2004). Assessment of hypotheses about dispersal in a long-lived seabird using multistate capture-recapture models. J. Anim. Ecol. 73, 723-736.

Chown, S.L., Klok, C.J. \& McGeoch, M.A. (2004). Weather to go out: activity of Bothrometopus brevis (Curculionidae) at Heard Island. Polar Biol. 27, 217-221.

Cumming, G.S. \& Bernard, R.T.F. (1997). Rainfall, food abundance and timing of parturition in African bats. Oecologia 111, 309-317.

Ellison, L.E. (2010). A retrospective survival analysis of Townsend's big-eared bat (Corynorhinus townsendii) from Washington State. Northwestern Naturalist 91, 172-182.

Entwistle, A.C., Racey, P.A. \& Speakman, J.R. (2000). Social and population structure of a gleaning bat Plecotus auritus. J. Zool. (London) 252, 11-17.

Gaines, M.S. \& McGlenaghan, L.R. (1980). Dispersal in small mammals. Ann. Rev. Ecol. Syst. 11, 163-196.

Gannon, W.L. \& Sikes, R.S. (2007). Guidelines of the American Society of mammalogists for the use of wild mammals in Research. J. Mammal. 88, 809-823.

Gerell, R. \& Lundberg, K. (1990). Sexual differences in survival rates of adult pipistrelle bats (Pipistrellus pipistrellus) in South Sweden. Oecologia 83, 401-404.

Greenwood, P.J. (1980). Mating systems, philopatry and dispersal in birds and mammals. Anim. Behav. 28, 1140-1162.

Happold, D.C.D. \& Happold, M. (1998). Effects of bat-bands and banding on a population of Pipistrellus nanus (Chiroptera: Vespertilionidae) in Malawi. Z. Saugetierkunde 63, 6578. 
Hargrove, J.W. \& Brady, J. (1992). Activity rhythms of tsetse flies (Glossina spp.) (Diptera:

Glossinidae) at low and high temperatures in nature. Bull. Entomol. Res. 82, 321-326.

Herreid, C.F., Davis, R.B. \& Short, H.L. (1960). Injuries due to bat banding. J. Mammal. 41, 398-400.

Hestbeck, J. B., Nichols, J. D. \& Malecki, R.A. (1991). Estimates of movement and site fidelity using mark-resight of wintering Canada geese. Ecology 72, 523-533.

Hillen, J., Kiefer, A., \& Veith, M. (2010). Interannual fidelity to roosting habitat and flight paths by female western barbastelle bats. Acta Chiropterologica, 12, 187-195.

Hitchcock, H. B., Keen, R. \& Kurta, A. (1984). Survival rates of Myotis leibii and Eptesicus fuscus in southeastern Ontario. J. Mammal. 65, 126-130.

Hood, G.M. (2010). PopTools version 3.2.5. Available on the internet. http://www.poptools.org Hoover, J.P. (2003). Decision rules for site fidelity in a migratory bird, the Prothonotary Warbler. Ecology 84, 416-430.

Hoyle, S.D., Pople, A.R. \& Toop, G.J. (2001). Mark-recapture may reveal more about ecology than about population trends: demography of a threatened ghost bat (Macroderma gigas) population. Austral Ecol. 26, 80-92.

Keen, R. \& Hitchcock, H.B. (1980). Survival and longevity of the little brown bat (Myotis lucifugus) in southeastern Ontario. J. Mammal. 61, 1-7.

Kerth, G. (2008). Causes and Consequences of Sociality in Bats. BioScience 58, 737-746.

Kerth, G., Mayer, F. \& Petit, E. (2002). Extreme sex-biased dispersal in the communally breeding, nonmigratory Bechstein's bat (Myotis bechsteinii). Mol. Ecol. 11, 1491-1498. 
Kerth, G., Perony, N. \& Schweitzer, F. (2011). Bats are able to maintain long-term social relationships despite the high fission-fusion dynamics of their groups. P. Roy. Soc. B: Biol. Sci. 278, 2761-2767.

Kingdon, J. (2004). The Kingdon Pocket Guide to African Mammals. Princeton: Princeton University Press.

Laake, J.L. (2013). RMark: An R Interface for Analysis of Capture-Recapture Data with MARK. AFSC Processed Rep 2013-01. Alaska Fish. Sci. Cent. Seattle: NOAA, Natl. Mar. Fish. Serv., 7600 Sand Point Way NE.

Lewis, S.E. (1995). Roost fidelity of bats: a review. J. Mammal. 76, 481-496.

Matthiopoulos, J., Harwood, J. \& Thomas, L. (2005). Metapopulation consequences of site fidelity for colonially breeding mammals and birds. J. Anim. Ecol. 74, 716-727.

Monadjem, A. (1998). Mammals of Swaziland. Mbabane: The Conservation Trust of Swaziland and Big Game Parks.

Monadjem, A. (2001). Sexual dimorphism, sex ratio and preliminary recapture rates of Nycteris thebaica (Nycteridae: Chiroptera) in Swaziland. Durban Mus. Novit. 26, 49-52.

Monadjem, A. (2005). Survival and roost-site selection in the African bat Nycteris thebaica (Chiroptera : Nycteridae) in Swaziland. Belg. J. Zool. 135, 103-107.

Monadjem, A. (2006). Longevity and movement of the common slit-faced bat Nycteris thebaica. African Bat Conserv. News. 9, 7.

Monadjem, A., \& Reside, A. (2008). The influence of riparian vegetation on the distribution and abundance of bats in an African savanna. Acta Chiropterol. 10, 339-348. 
Monadjem, A., Raabe, T., Dickerson, B., Silvy, N. \& McCleery, R. (2010b). Roost use by two sympatric species of Scotophilus in a natural environment. S. Afr. J. Wildl. Res. 40, 7376.

Monadjem, A., Reside, A., Cornut, J. \& Perrin, M.R. (2009). Roost selection and home range of an African insectivorous bat Nycteris thebaica (Chiroptera, Nycteridae). Mammalia 73, $353-359$.

Monadjem, A., Taylor, P.J., Cotterill, F.P.D. \& Schoeman, M.C. (2010a). Bats of southern and central Africa: a biogeographic and taxonomic synthesis. Johannesburg: University of Witwatersrand Press.

O’Shea, T.J., Ellison, L.E. \& Stanley, T.R. (2004). Survival estimation in bats: historical overview, critical appraisal, and suggestions for new approaches. In Sampling rare or elusive species: concepts, designs, and techniques for estimating population parameters: 297-336. Thompson, W.L. (Ed). Washington D.C.: Island Press.

Otis, D.L., Burnham, K.P., White, G.C. \& Anderson, D. R. (1978). Statistical inference for capture data from closed populations. Wildlife Monograph 62, $135 \mathrm{pp}$.

Papadatou, E., Butlin, R.K., Pradel, R. \& Altringham, J.D. (2009). Sex-specific roost movements and population dynamics of the vulnerable long-fingered bat, Myotis capaccinii. Biol. Conserv. 142, 280-289.

Papadatou, E., Ibanez, C., Pradel, R., Juste, J. \& Gimenez, O. (2011). Assessing survival in a multi-population system: a case study on bat populations. Oecologica 165, 925-933.

Pryde, M.A., O’Donnell, C.F.J. \& Barker, R. (2005). Factors influencing survival and long-term population viability of New Zealand longtailed bats (Chalinolobus tuberculatus): implications for conservation. Biol. Conserv. 126, 175-185. 
R Development Core Team. (2013). R: A language and environment for statistical computing. R. Foundation for Statistical Computing, Vienna, Austria. http://www.R-project.org.

Sandercock, B. K., Beissinger S. R., Stoleson S. H., Melland R. R., \& Hughes C. R. 2000. Survival rates of a Neotropical parrot: Implications for latitudinal comparisons of avian demography. Ecology 81, 1351-1370.

Schaub, M., Gimenez, O., Schmidt, B.R. \& Pradel, R. (2004). Estimating survival and temporary emigration in the Multistate capture-recapture framework. Ecology 85, 2107-2113.

Schaub, M., Gimenez, O., Sierro, A. \& Arlettaz, R. (2007). Use of integrated modeling to enhance estimates of population dynamics obtained from limited data. Conserv. Biol. 21, 945-955.

Schorcht, W., Bontadina, F. \& Schaub, M. (2009). Variation of adult survival drives population dynamics in a migrating forest bat. J. Anim. Ecol. 78, 1182-1190.

Sendor, T., \& Simon, M. (2003). Population dynamics of the pipistrelle bat: effects of sex, age and winter weather on seasonal survival. J. Appl. Ecol. 72, 308-320.

Serrano, D., Tella, J.L., Forero, M.G. \& Donázar, J.A. (2001). Factors affecting breeding dispersal in the facultatively colonial lesser kestrel: individual experience vs. conspecific cues. J. Anim. Ecol. 70, 568-578.

Stearns, S.C. (1983). The influence of size and phylogeny on patterns of covariation among lifehistory traits in the mammals. Oikos 41, 173-187.

Stevenson, D.E. \& Tuttle, M.D. (1981). Survivorship in the endangered gray bat (Myotis grisescens). J. Mammal. 62, 244-257. 
Trajano, E. (1996). Movements of Cave Bats in Southeastern Brazil, with Emphasis on the Population Ecology of the Common Vampire Bat, Desmodus rotundus (Chiroptera). Biotropica 28,121-129.

White, G. C. \& K. P. Burnham. (1999). Program MARK: Survival estimation from populations of marked animals. Bird Study 46(Supplement), 120-139.

Wilson, D.E. \& Reader, D.M. (2005). Mammalian species of the World. Baltimore: The John Hopkins University Press. 